\title{
The effect of ethanol sclerotherapy of 5 minutes duration on cyst diameter and rat ovarian tissue in simple ovarian cysts
}

This article was published in the following Dove Press journal:

Drug Design, Development and Therapy

5 March 2015

Number of times this article has been viewed

\author{
Mehmet Șimșek' \\ Tuncay Kuloğlu² \\ Șehmus Pala ${ }^{3}$ \\ Abdullah Boztosun ${ }^{4}$ \\ Behzat Can' \\ Remzi Atilgan' \\ 'Department of Obstetrics and \\ Gynecology, ${ }^{2}$ Department of \\ Histology, Firat University School \\ of Medicine, Elazig, Turkey; ${ }^{3}$ Clinic \\ of Obstetrics and Gynecology, \\ Batman Yasam Hospital, Batman, \\ Turkey; ${ }^{4}$ Department of Obstetrics \\ and Gynecology, Akdeniz University \\ School of Medicine, Antalya, Turkey
}

Correspondence: Remzi Atilgan

Department of Obstetrics and Gynecology, Firat University School of Medicine, Universite Mah, Yunus Emre

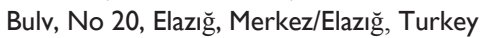
Tel +904242333555 ext 2118 Email remzi_atilgan@hotmail.com
Objectives: To examine the effect of 95\% ethanol sclerotherapy (EST) administered over 5 minutes on cyst diameter and ovarian tissue in experimentally induced simple ovarian cysts in a rat model.

Materials and methods: In order to induce ovarian cysts, unilateral total salpingectomy was performed in regularly menstruating adult female Wistar albino rats $(n=20)$ between 12 and 14 weeks of age and weighing between 200 and $220 \mathrm{~g}$. One month after the procedure, the abdominal cavity was opened and 14 rats $(70 \%)$ were found to have developed macroscopic cysts. Rats with macroscopic cysts $(n=14)$ were assigned into two groups in a prospective and single-blinded manner: group 1 (G1) $(n=7)$, control rats; and group 2 (G2) (n=7), 5-minute EST 95\% group. Cyst diameter was measured and recorded for each rat. In G2, after whole cyst fluid was aspirated the cystic cavity was irrigated with $95 \%$ ethanol, approximately equal to half of the aspirated cyst volume, after which an interval of 5 minutes was allowed and same amount was re-aspirated and the abdominal cavity was closed. One month after this procedure, abdominal cavities were reopened and intra-abdominal adhesion scoring was performed in both groups. Cyst diameter was measured for each rat, and the right ovary was removed, fixed in 10\% formaldehyde, and transported to the laboratory. A histologic assessment of the ovarian tissues was performed under light microscopy following staining with hematoxylin and eosin. Mann-Whitney $U$-test was used for statistical analysis. A $P$-level less than 0.05 was considered significant.

Results: In comparison with G1, there was a statistically significant reduction in the mean ovarian cyst dimensions in G2, while there were no significant differences between the two groups with respect to total number of follicles. Again, a significant increase in apoptotic activity and germinal epithelial degeneration was observed in G2 as compared to G1. The two groups were similar in terms of adhesion formation.

Conclusion: Although 95\% EST results in a reduction in the size of simple ovarian cysts, this effect seems to be achieved at the expense of ovarian tissue injury.

Keywords: ethanol instillation, salpingectomy, ovarian morphology, simple ovarian cyst, adhesion

\section{Introduction}

While follicular or lutein functional cysts comprise the majority of cystic ovarian lesions, occasionally a serous cystadenoma may result in the formation of an ovarian cyst. The average size of the follicular cysts ranges from microscopic to $4 \mathrm{~cm}$, while rarely they may have greater dimensions. The inner walls of these cysts are lined by granulosa cells. Lutein cysts are generally categorized into the two following groups: theca lutein cysts associated with granulosa lutein or mol hydatidiform, and corpus luteum (CL) cysts. Benign serous tumors are generally unilocular with a smooth 
surface and yellowish fluid content. Similarly, cystic tumors have a smooth and shiny appearance of the inner and outer walls. In the lower part of the cysts, columnar epithelial cells represent the dominant cell type and most have cilia. In some other areas in the cyst wall, cuboidal or nail-like epithelial cells may also be observed. The border between epithelium and stroma is lined by the basal membrane. Cysts up to $4 \mathrm{~cm}$ generally resolve spontaneously within 2-3 months. If the cyst is persistent or continues to grow (eg, 5-6 cm growth), cyst aspiration or operation is recommended. ${ }^{1}$

However, aspiration may be associated with certain challenges including high recurrence rate, difficulty in histological diagnosis, infections, and potential effects on the reproductive performance. In this regard, ethanol sclerotherapy (EST) has been used as a therapeutic modality in the management of benign cysts originating from a number of different organ systems such as thyroid, parathyroid, heart, liver, spleen, kidneys, and ovarian cysts. ${ }^{2-11}$

Alcohol is a sclerosing agent, and following the exposure of the epithelial cell layer of the cyst to the effects of alcohol, the cyst becomes nonviable. ${ }^{12}$ Ethanol diffuses into tissues, resulting in the induction of dehydration, protein denaturation, coagulation necrosis, and reactive fibrosis. ${ }^{13}$

\section{Objectives}

To examine the effect of 95\% EST administered over a 5 -minute time period on the dimensions of the cyst and ovarian tissue in rats with experimentally induced ovarian cysts.

\section{Materials and methods}

This experimental study was conducted at the Laboratory for Animal Experimentation, Firat University, Elazı̆̆ Turkey.

\section{Animals}

A total of 20 regularly menstruating Wistar albino rats aged 12-14 weeks and weighing between 200 and $200 \mathrm{~g}$ were kept in temperature-controlled cages (five in each) at 12-hour light/12-hour dark cycle and were fed with standard pellet food and tap water.

\section{Experimental design}

The study protocol was approved by the Ethics Committee of Frrat University. Eighteen hours prior to the experiment, oral feeding was stopped and only water was allowed. Rats in the osteogenic phase, as documented by the vaginal cytological monitoring, were placed under anesthesia with ketamine and xylazine. Ketamine $\mathrm{HCl}$ (Ketalar; Eczacıbaşı Warner-Lambert, Istanbul, Turkey) at room temperature $\left(20^{\circ} \mathrm{C}\right)$ was administered at a dose of $60 \mathrm{mg} / \mathrm{kg}$ and xylazine hydrochloride (Rompun; Bayer AG, Leverkusen, Germany) was administered at a dose of $7 \mathrm{mg} / \mathrm{kg}$ intramuscularly at the left hind leg. Rats were placed in supine position and a midline abdominal incision was made.

\section{Surgical technique}

In order to induce the development of ovarian cysts, the method proposed by Atilgan et al was used. ${ }^{14,15}$ After unilateral total salpingectomy was performed and hemostasis was achieved, the incision was closed using 3-0 silk with single sutures. One month after the initial procedure, abdominal cavities were reopened and formation of macroscopic ovarian cysts was detected in 14 (70\%) rats (Figure 1). Fourteen rats with macroscopic cysts were randomly assigned into two groups prospectively in a single-blinded manner. Group 1 $(\mathrm{G} 1)(\mathrm{n}=7)$ consisted of rats with aspiration of the intracystic

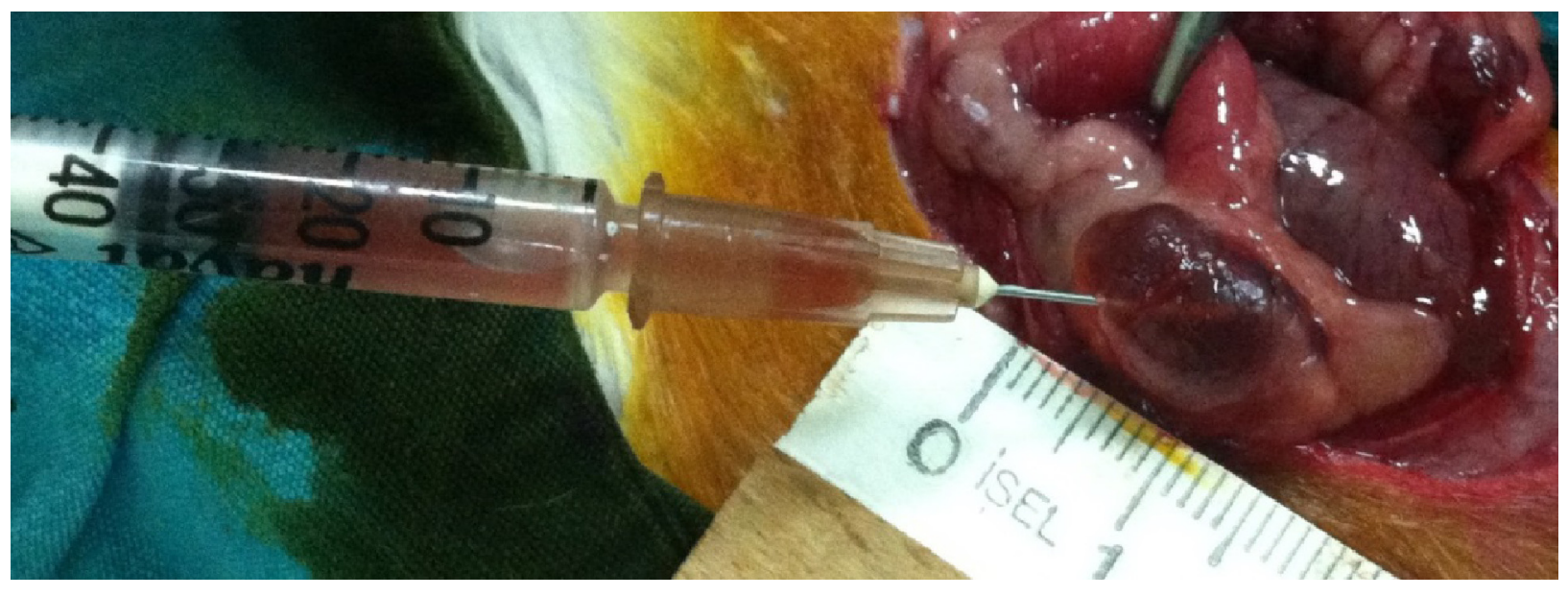

Figure I Group I, macroscopic ovarian cyst and cyst aspiration with insulin syringe. 
fluid only, followed by closure of the abdominal cavity. In group 2 (G2) (n=7), after whole cyst fluid was aspirated, the cystic cavity was irrigated with $95 \%$ ethanol approximately equal to half of the aspirated cyst volume, after which an interval of 5 minutes was allowed, the same amount was reaspirated, and the abdominal cavity was closed using 3-0 silk sutures, as above. For intracystic injections and aspirations, insulin injectors were utilized (Figure 1). During the procedure, the cyst dimensions were measured and recorded.

One month after the procedure, abdominal cavities of animals in both G1 and G2 were reopened and an adhesion scoring was performed. ${ }^{16}$ Also, presence and dimensions of cysts were examined and recorded.

\section{Adhesion size}

- No adhesions $=0$ point

- Adhesions in $25 \%$ of the traumatized area $=1$ point

- Adhesions in $25 \%-50 \%$ of the traumatized area $=2$ points

- Adhesions in 50\%-100\% of the traumatized area $=3$ points.

\section{Adhesion severity}

- No resistance to surgical manipulation $=0$ point

- Moderate resistance to surgical manipulation $=0.5$ points

- Significant resistance requiring sharp dissection $=1$ point.

\section{Histological examination}

Each rat's right ovary was removed, fixed in 10\% formaldehyde, and transported to the laboratory. Then, paraffin blocks were prepared for histologic and histochemical assays. The $5 \mu \mathrm{m}$ thick cross-sections obtained from the paraffin blocks were stained with Masson's trichrome staining and examined and photographed under light microscopy (Olympus BX-50; Olympus Corporation, Tokyo, Japan).

\section{Terminal deoxynucleotidyl transferase dUTP nick end labeling (TUNEL) staining}

Cross-sections of 5-6 $\mu \mathrm{m}$ thickness from the paraffin blocks were placed onto microscopic slides. Cells with apoptotic activity were determined using ApopTag Plus Peroxidase In Situ Apoptosis Detection Kit (catalog number: S7101; Chemicon International, Temecula, CA, USA) in accordance with the relevant information provided by the manufacturer. Nuclei staining blue with Harris hematoxylin were considered normal, while those staining brown were considered apoptotic. The extent of the staining was used as the primary assessment criteria in the evaluation of TUNEL staining.

Using light microscopy and methods described by Souza et $a 1^{17}$ follicular reserve (primordial, primary, secondary, and tertiary follicle number) and presence of fibrosis were assessed. For the microscopic description of follicles, the approach described by Mazaud et a $1^{18}$ was utilized in the following manner:

- Primordial: oocyte partially or completely surrounded by flattened pre-granulosa cells

- Primary: enlarged oocyte with one layer of cuboidal cells, or at least one cuboidal cell among flattened granulosa cells

- Secondary: two layers of granulosa cells or at least one layer and one cell of the second layer

- Preantral: oocyte enclosed by more than two layers of granulosa cells, no antrum formation

- Antral: oocyte enclosed by more than two layers of granulosa cells with antrum formation

- Atretic preantral: degenerating oocyte or at least two pyknotic granulosa cells

- Atretic antral: granulosa cell pyknosis; granulosa cell pyknosis with degenerating oocyte; degenerated oocyte with few pyknotic granulosa cells and hypertrophied theca interna.

The extent of fibrosis was assessed semiquantitatively in a 4-point scale (0-3) using Masson's trichrome staining: ${ }^{19,20}$

- $0=$ no fibrosis

- $1=$ mild fibrosis

- $2=$ moderate fibrosis

- $3=$ severe fibrosis.

Similarly, apoptosis was determined semiquantitatively as follows: ${ }^{21}$

- $0=$ no apoptotic activity

- $1=$ mild apoptotic activity

- $2=$ moderate apoptotic activity

- $3=$ significant apoptotic activity.

Angiogenesis in the CL was scored as follows: ${ }^{22,23}$

$$
\text { HSCORE }=\Sigma \mathrm{Pi}(\mathrm{i}+1)
$$

where $\mathrm{Pi}=$ the percentage of stained cells and $\mathrm{i}=$ intensity of staining with a value of,, \pm+++ , or +++ (minimal, mild, moderate, or strong, respectively);

- $0=$ none

- $1=$ mild angiogenesis

- $2=$ moderate angiogenesis

- $3=$ significant angiogenesis. 


\section{Statistical analyses}

Data analysis was performed using SPSS 17.0 for Windows (SPSS Inc., Chicago, IL, USA). Following a Kruskal-Wallis analysis of variance, between-group comparisons for parameters with a significance level of less than 0.05 were performed with Mann-Whitney $U$ (MWU) test. A $P$-value less than 0.05 was considered statistically significant.

\section{Results}

The experimental protocol was successfully completed in all rats. The average diameter of the ovarian cyst before and after aspiration in G1 was 10.5 $\pm 1.9(9-14) \mathrm{mm}$ and $8.1 \pm 1.6$ (6-11) mm, respectively. Cyst diameters for the overall study group are depicted in Table 1. Aspiration did not result in a significant reduction in the diameter of the cyst $(P>0.05$, MWU test). In G2, the average cyst diameters before and after EST were 10.4 $\pm 2.2(8-15) \mathrm{mm}$ and $5.7 \pm 1.3(3-7) \mathrm{mm}$, respectively. The average volume of aspirated cyst fluid was $0.6 \pm 0.3(0.3-1.4) \mathrm{mL}$, while the average volume of ethanol injected into the cysts was $0.3 \pm 0.1(0.15-0.70) \mathrm{mL}$. Preaspiration cyst diameter in $\mathrm{G} 1$ was not significantly different from pre-EST cyst diameter in G2 ( $P>0.05$, MWU test). However, there was a significant difference between postaspiration cyst diameter in $\mathrm{G} 1$ and post-EST cyst diameter in $\mathrm{G} 2(P<0.05$, MWU test). Thus, EST resulted in a significant reduction in the cyst diameter as compared to those in the aspiration-alone group $(P<0.05$, MWU test) (Table 1$)$.

G1 and G2 did not differ significantly in terms of total number of follicles; primordial, secondary, and tertiary follicles; and $C L$ and corpus albicans $(P>0.05)$. However, there was a significant decrease in the number of primary follicles in G2 $(P<0.05)$. All relevant data is shown in Table 2 and Figure 2.

There was a significant decline in the angiogenic activity within $\mathrm{CL}$ in $\mathrm{G} 2(P<0.05)$. Although there was a numerically higher fibrosis score in $\mathrm{G} 2$, the difference was not significant $(P>0.05)$.

Apoptotic activity and ovarian germinal epithelial degeneration was significantly higher in $\mathrm{G} 2$ than in $\mathrm{G} 1(P<0.05)$ (Table 2; Figure 3).

No significant differences were observed between the two groups in terms of the extent and severity of intra-abdominal adhesions $(P>0.05)$ (Table 2).

\section{Discussion}

Although EST 95\% administered over a 5-minute period was effective in reducing the dimensions of ovarian cysts, it was also associated with detrimental effects on ovarian tissues without significantly reducing the number of total follicles.

In our study, simple ovarian cysts were induced in rats by unilateral total salpingectomy. Previous experimental studies have shown that left total salpingectomy was associated with reduced rate of decrease in angiogenesis, increased number of atretic follicles, increased ovarian stromal fibrosis, and development of macroscopic follicular cysts. ${ }^{14,15,20}$ In our experiment, following unilateral total salpingectomy, macroscopic ovarian cysts were formed in $70 \%$ of the cases. In our study, ethanol was administered at a volume of approximately $50 \%$ of the aspirated fluid from the cyst and was aspirated back after 5 minutes. This was the preferred method of administration due to the observation by Tei et $\mathrm{al}^{24}$ that $110 \mathrm{~mL}$ of ethanol administered into endometrium led to signs of acute alcoholism (the depression of the higher nerve centers, impaired motor control, stupor, lack of coordination, nausea, headache, dehydration, and other physical symptoms). Thus, in these animals, ethanol was aspirated after 5 minutes.

In cases who received EST, several effects including intestinal perforation, shedding of the neoplastic cells from the peritoneal cavity, intestinal sclerosis, extensive adhesion, or bacterial infections have been reported..$^{5,6,10,13}$ In our study,

Table I Cyst diameter $(\mathrm{mm})$ before and after aspiration; cyst diameter $(\mathrm{mm})$ before and after EST; cyst volume ( $\mathrm{mL})$ aspired before EST; and ethanol volume $(\mathrm{mL})$ given in cyst

\begin{tabular}{lllllll}
\hline Rat $(\mathbf{n})$ & $\begin{array}{l}\text { Cyst diameter } \\
\text { before aspiration } \\
(\mathbf{m m})\end{array}$ & $\begin{array}{l}\text { Cyst diameter } \\
\text { after aspiration } \\
(\mathbf{m m})\end{array}$ & $\begin{array}{l}\text { Cyst diameter } \\
\text { before EST } \\
(\mathbf{m m})\end{array}$ & $\begin{array}{l}\text { Intracystic fluid } \\
\text { volume aspirated } \\
\text { before EST }(\mathbf{m L})\end{array}$ & $\begin{array}{l}\text { Ethanol volume } \\
\text { given in EST } \\
(\mathbf{m L})\end{array}$ & $\begin{array}{l}\text { Cyst diameter } \\
\text { after EST } \\
(\mathbf{m m})\end{array}$ \\
\hline 1 & 9 & 7 & 8 & 0.3 & 0.15 & 6 \\
2 & 11 & 9 & 11 & 0.5 & 0.25 & 7 \\
3 & 9 & 6 & 9 & 0.4 & 0.20 & 6 \\
4 & 10 & 9 & 10 & 0.5 & 0.25 & 5 \\
5 & 14 & 11 & 15 & 1.4 & 0.70 & 3 \\
6 & 12 & 7 & 9 & 0.4 & 0.20 & 6 \\
7 & 9 & 8 & 11 & 0.8 & 0.40 & 7 \\
Mean & $10.5 \pm 1.9$ & $8.1 \pm 1.6$ & $10.4 \pm 2.2$ & $0.6 \pm 0.3$ & $0.3 \pm 0.1$ & $5.7 \pm 1.3$ \\
\hline
\end{tabular}

Abbreviation: EST, ethanol sclerotherapy. 
Table 2 Evaluated histologic parameters and adhesion scores related to both groups

\begin{tabular}{llll}
\hline Parameters & G I & G2 & P \\
\hline Primordial follicle count & $16.4 \pm 2.6$ & $12.5 \pm 3.2$ & $\mathrm{Ns}$ \\
Primary follicle count & $12.7 \pm 1.7$ & $9.7 \pm 1.2$ & $*$ \\
Secondary follicle count & $9.1 \pm 1.5$ & $7.1 \pm 2.1$ & $\mathrm{Ns}$ \\
Tertiary follicle count & $3.1 \pm 0.8$ & $2.5 \pm 0.5$ & $\mathrm{Ns}$ \\
Ovarian follicular reserve & $40.8 \pm 5.6$ & $33 \pm 0.5$ & $\mathrm{Ns}$ \\
CL count & $0.8 \pm 0.6$ & $\mathrm{I} \pm 0$ & $\mathrm{Ns}$ \\
Corpus albicans count & $0 \pm 0$ & $0 \pm 0$ & $\mathrm{Ns}$ \\
Angiogenesis in CL & $1.6 \pm 0.5$ & $0.7 \pm 0.2$ & $*$ \\
Fibrosis & $0.8 \pm 0.2$ & $1.2 \pm 0.4$ & $\mathrm{Ns}$ \\
Apoptosis & $0.4 \pm 0.5$ & $1.8 \pm 0.6$ & $*$ \\
Germinal epithelial degeneration & $0.8 \pm 0.2$ & $2 \pm 0.5$ & $*$ \\
Surface area of adhesion & $1.5 \pm 0.7$ & $1.7 \pm 0.9$ & $\mathrm{Ns}$ \\
Severity of adhesion & $0.6 \pm 0.2$ & $0.7 \pm 0.2$ & $\mathrm{Ns}$ \\
\hline
\end{tabular}

Notes: Values presented as means \pm standard deviation. $* P<0.05$, Mann-Whitney U-test.

Abbreviations: $\mathrm{CL}$, corpus luteum; GI, group I; G2, group 2; Ns, nonsignificant.

none of these complications have been observed, probably due to the administration of EST with laparotomy under better controlled conditions.

Kukura et al ${ }^{12}$ have reported that $95 \%$ EST may be a feasible and practical therapeutic modality for the treatment of simple ovarian cysts in humans. These authors treated a total of 90 younger patients with controlled cyst rupture alone without EST, with a relapse rate of $24.44 \%$ $(\mathrm{n}=22)$ after 3 months. On the other hand, 42 cases received concentrated EST. Two cases (4.76\%) with intracystic fluid volume greater than $100 \mathrm{~mL}$ relapsed. No menstrual disorders were observed after 3, 6, and 12 months of follow-up, with no adverse effects on the total ovarian follicle number after 1 month. In our study, although 95\% EST administered over a 5-minute period did not result in a change in the number of total ovarian follicles 1 month after treatment, a significant decrease in the number of primary follicles was observed. The number of secondary follicles was also reduced, although the reduction was not statistically significant. These findings suggest that 5-minute administration of EST may be associated with adverse consequences in terms of ovarian reserve in the long-term. Further experimental studies with a longer interval between the first and second laparotomy may provide more insights on the impact on the ovarian reserve.

Koike et $\mathrm{al}^{25}$ reported that a 5-minute application of ethanol suffices for the fixation of the inner layer of the ovarian endometriotic cysts and may avoid adverse effects on the ovarian tissue. Again, these authors observed no negative effects of EST on reproductive performance in women with ovarian endometrioma. Similarly Yazbeck et $\mathrm{al}^{26}$ found no negative effects of EST on ovarian reserve. In an experimental study by Atilgan et $\mathrm{al}^{15}$ the duration of administration was 10 minutes, with significant reduction in the size of the ovarian cysts 1 month after treatment. However, they also detected
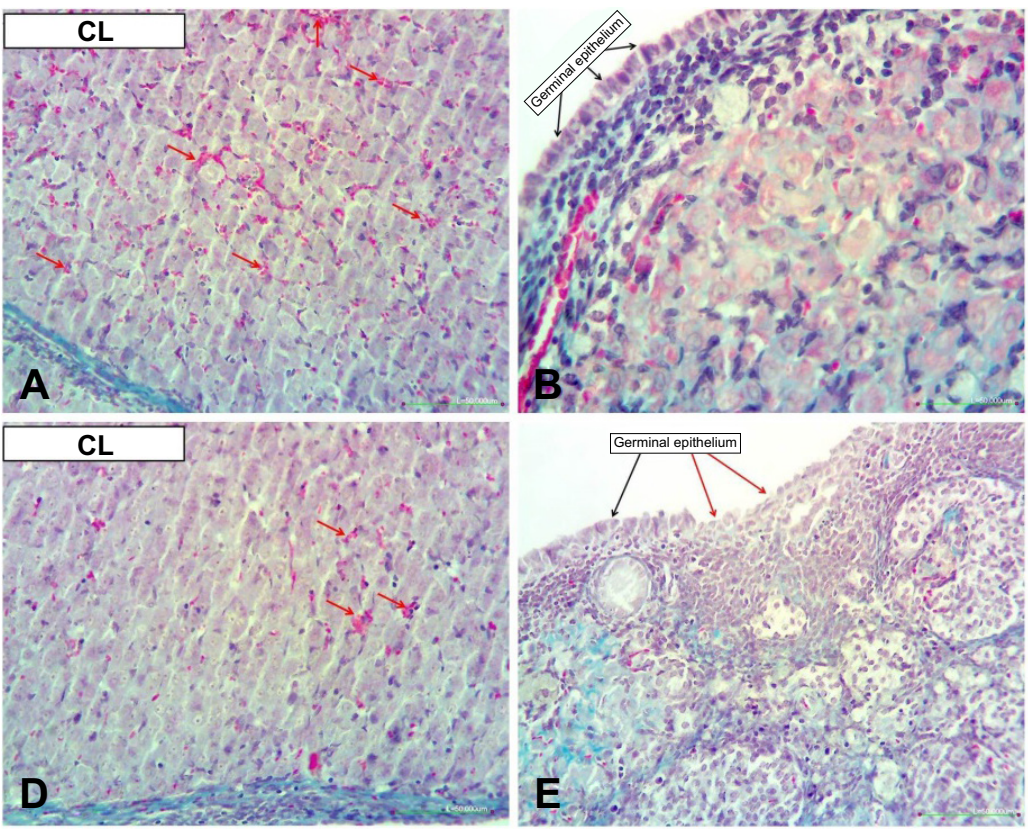
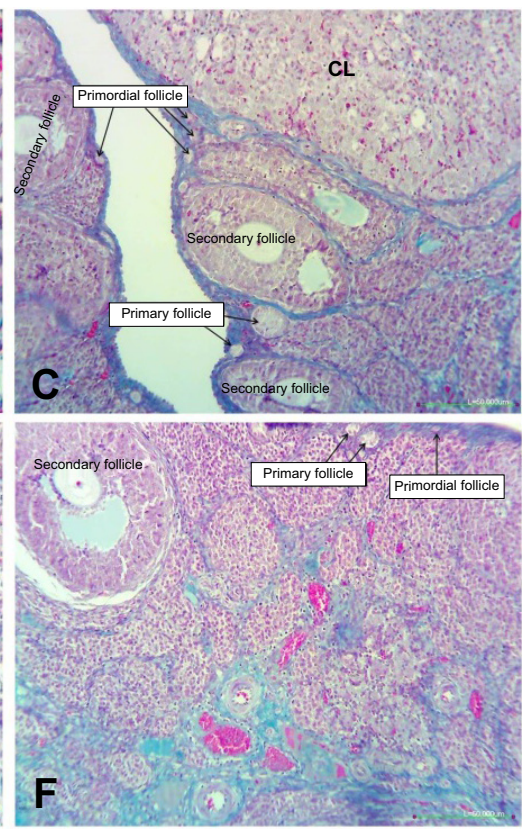

Figure 2 Histological sections were stained with Masson's trichrome and assessed under light microscope.

Notes: Group I: (A) angiogenesis in CL (red arrow); (B) germinal epithelium; (C) different follicle types. Group 2: (D) angiogenesis in CL (red arrow); (E) germinal epithelium; (F) different follicle types.

Abbreviation: $\mathrm{CL}$, corpus luteum. 

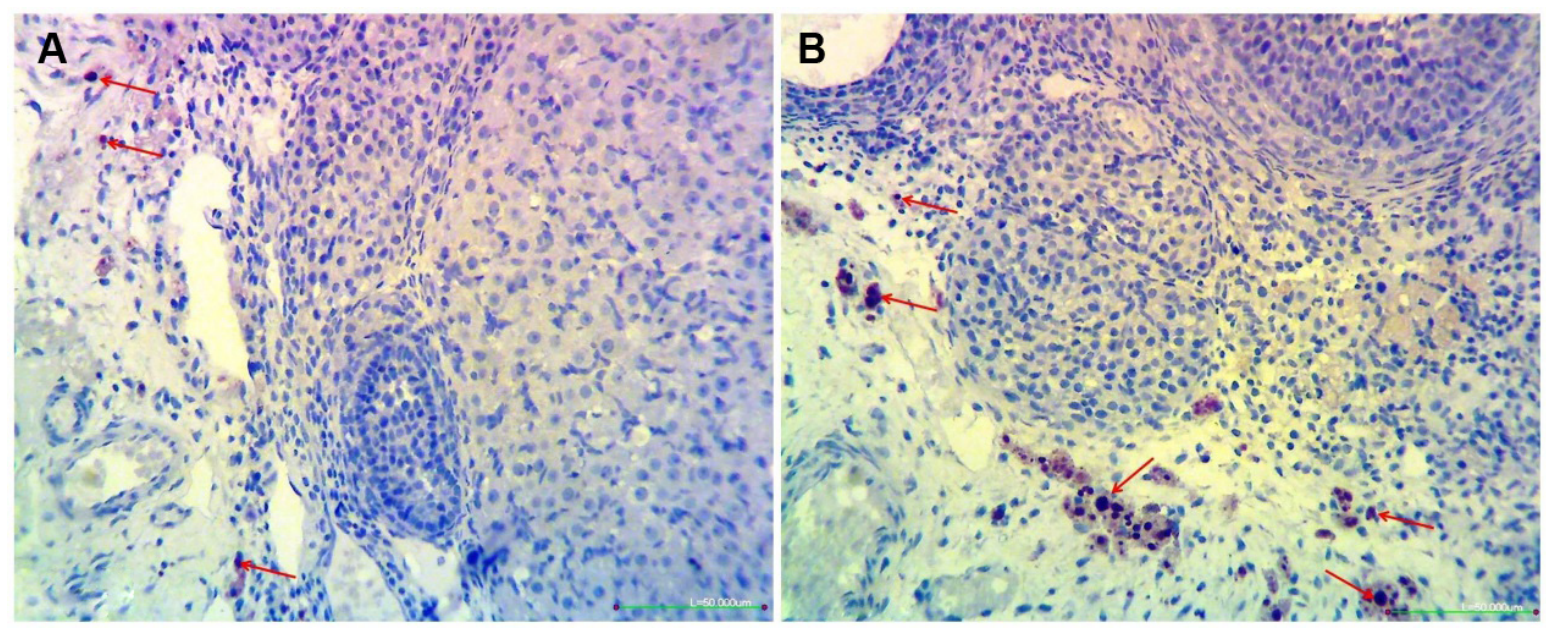

Figure 3 The extensity of TUNEL staining in both groups; histological sections were assessed for apoptosis by TUNEL. Notes: (A) Group I, (B) group 2. Red arrows: TUNEL-positive cells.

Abbreviation: TUNEL, terminal deoxynucleotidyl transferase dUTP nick end labeling.

significant fibrosis and apoptosis in the ovarian tissues along with reduced ovarian reserve. In our experiment, a 5-minute fixation resulted in a significant reduction in the size of the simple ovarian cysts also. Despite the absence of any difference with regard to the degree of fibrosis between the two groups, a marked degeneration and a significant increase in apoptotic activity were found in the ovarian germinal epithelium of the EST group. Thus, our findings differ from those of Koike et $\mathrm{a}^{25}$ with respect to the differences in the cyst wall thickness and species tested. On the other hand, the difference in the duration of administration of ethanol may account for the differences between our findings and those of Atilgan et al's. ${ }^{15}$

In studies examining the renal cyst specimens, EST was found to penetrate into the cyst wall and to cause fixation. ${ }^{9}$ Epithelial cells have been reported to be non-viable 1-3 minutes after fixation with alcohol. However, penetration of ethanol into the cyst capsule has been reported to require 4-12 hours. ${ }^{9}$ In Atilgan et al's ${ }^{15}$ study, alcohol administration was performed for 10 minutes, with consequent negative effects on ovarian tissues. In our study, even a shorter duration of treatment (ie, 5 minutes) resulted in epithelial degeneration of the germinal epithelium and increased apoptotic activity.

There was a significant reduction of the angiogenesis score of CL in G2, consistent with those reported by Atilgan et $a l^{15}$ who suggested that this may be due to increased ovarian hypoxia following total salpingectomy. Also, these authors reported that tissue penetration of ethanol results in decreased angiogenesis within the $\mathrm{CL}$, and that persistence of the ovarian cysts in the aspiration group may be the result of increased angiogenesis.
Hsieh et $\mathrm{al}^{27}$ reported that $95 \%$ EST provided an effective treatment in patients with endometrioma as documented by ultrasound, with no reduction in the antral follicles. Similarly, we did not observe a significant difference between the two groups in terms of the number of secondary follicles.

In contrast with the abovementioned studies, we also assessed development of postoperative intra-abdominal adhesions in both groups, since manipulation with hand maneuvers or surgical equipment during surgery is a principle cause of postoperative peritoneal adhesions. ${ }^{28,29}$ Also, peritoneal irritation may also cause intra-abdominal adhesions via the development of chemical peritonitis. ${ }^{30}$ In this experimental model, total salpingectomy and cyst aspiration procedures requiring mechanical and instrumental manipulations were thought to increase the potential for the formation of intraabdominal adhesions. Therefore, the two groups were also compared with regard to adhesion scores, with no significant differences. This finding suggests that a 5-minute administration of ethanol may not allow penetration of ethanol into the cyst wall, precluding the formation of adhesions due to the absence of chemical peritonitis.

\section{Conclusion}

Although 5-minute administration of 95\% EST results in a reduction in the dimensions of simple ovarian cysts in rats, the results clearly suggest a detrimental effect of EST in ovarian tissue.

\section{Disclosure}

All authors declare that they have no conflict of interest in this work. 


\section{References}

1. Mittal S, Kumar S, Kumar A, Verma A. Ultrasound guided aspiration of endometrioma - a new therapeutic modality to improve reproductive outcome. Int J Gynaecol Obstet. 1999;65(1):17-23.

2. Aboulghar MA, Mansour RT, Serour GI, Rizk B. Ultrasonic transvaginal aspiration of endometrial cysts: an optional line of treatment in selected cases of endometriosis. Hum Reprod. 1991;6:1408-1410.

3. Marana R, Caruana P, Muzii L, Catalano GF, Mancuso S. Operative laparoscopy for ovarian cysts: Excision vs aspiration. J Reprod Med. 1996;41:435-438.

4. Fromholt Larsen J, Due Pedersen O, Gregersen E. Ovarian cyst fenestration via the laparoscope. A laparoscopic method for treatment of non-neoplastic ovarian cysts. Acta Obstet Gynecol Scand. 1986;65:539-542.

5. Zanetta G, Lissoni A, Torri V, et al. Role of puncture and aspiration in expectant management of simple ovarian cysts: a randomized study. BMJ. 1996;313:1110-1113.

6. Trimbos JB, Hacker NF. The case against aspirating ovarian cysts. Cancer. 1993;72:828-831.

7. Okagaki R, Osuga Y, Momoeda M, Tsutsumi O, Taketani Y. Laparoscopic findings after ultrasound-guided transvaginal ethanol sclerotherapy for ovarian endometrial cyst. Hum Reprod. 1999;14:270.

8. Antonelli A, Campatelli A, Di Vito A, et al. Comparison between ethanol sclerotherapy and emptying with injection of saline in treatment of thyroid cysts. Clin Invest. 1994;72:971-974.

9. Bean WJ. Renal cysts: treatment with alcohol. Radiology. 1981;138: 329-331.

10. Akamatsu N, Hirai T, Masaoka H, Sekiba K, Fujita T. [Ultrasonically guided puncture of endometrial cysts - aspiration of contents and injection of ethanol]. Nihon Sanka Fujinka Gakkai Zasshi. 1988;40:187-191. Japanese.

11. Bret PM, Atri M, Guibaud L, Gillett P, Seymour RJ, Senterman MK. Ovarian cysts in postmenopausal women: preliminary results with transvaginal alcohol sclerosis. Work in progress. Radiology. 1992; 184:661-663.

12. Kukura V, Krivak-Bolanca I, Sentija K, Katalenić-Simon S. Alcohol sclerosing ovarian cystic lesions, 20 years experience. Coll Antropol. 2010;34(1):37-40

13. Livraghi T, Paracchi A, Ferrari C, et al. Treatment of autonomous thyroid nodules with percutaneous ethanol injection: preliminary results. Work in progress. Radiology. 1990;175:827-829.

14. Atilgan R, Celik A, Sapmaz E, et al. [The Effect Of Unilateral Salpıngectomy On Ovarian Histopathological Examınation: An Experımental Study]. Turkiye Klinikleri J Gynecol Obst. 2005;15: 235-242. Turkish.

15. Atilgan R, Ozkan ZS, Kuloglu T, et al. Impact of intracystic ethanol instillation on ovarian cyst diameter and adjacent ovarian tissue. Eur J Obstet Gynecol Reprod Biol. 2014;174:133-136.

16. Linsky CB, Diamond MP, Cunningham T, Constantine B, DeCherney AH, diZerega GS. Adhesion reduction in the rabbit uterine horn model using an absorbable barrier, TC-7. J Reprod Med. 1987;32: $17-20$.
17. Souza AZ, Fonseca AM, Izzo VM, Clauzet RM, Salvatore CA. Ovarian histology and function after total abdominal hysterectomy. Obstet Gynecol. 1986;68(6):847-849.

18. Mazaud S, Guigon CJ, Lozach A, et al. Establishment of the reproductive function and transient fertility of female rats lacking primordial follicle stock after fetal gamma-irradiation. Endocrinology. 2002; $143: 4775-4787$.

19. Samrao D, Wang D, Ough F, et al. Histologic parameters predictive of disease outcome in women with advanced stage ovarian carcinoma treated with neoadjuvant chemotherapy. Transl Oncol. 2012;5(6): 469-474.

20. Sapmaz E, Kale A, Akpolat N. Melatonin use in unilateral total salpingectomy in rats. Clin Exp Obstet Gynecol. 2012;39(2): 186-190.

21. Suzuki S, Toledo-Pereyra LH, Rodriguez FJ. Role of neutrophils during the first 24 hours after liver ischemia and reperfusion injury. Transplant Proc. 1994;26:3695-3700.

22. Altungül AC, Kale A, Sapmaz E, Akpolat N. Examination of the effect of melatonin use in Pomeroy method of tubal ligation on ovarian histology in rats. Clin Exp Obstet Gynecol. 2012;39(1):103-106.

23. Inan S, Vatansever S, Celik-Ozenci C, Sanci M, Dicle N, Demir R. Immunolocalizations of VEGF, its receptors flt-1, KDR and TGFbeta's in epithelial ovarian tumors. Histol Histopathol. 2006; 21(10):1055-1064.

24. Tei A, Ueki M, Yokono S, Ogli K. [Acute alcoholism after ethanol fixation for ovarian chocolate cyst]. Masui. 1996;45(4):496-499. Japanese.

25. Koike T, Minakami H, Motoyama M, Ogawa S, Fujiwara H, Sato I. Reproductive performance after ultrasound-guided transvaginal ethanol sclerotherapy for ovarian endometriotic cysts. Eur J Obstet Gynecol Reprod Biol. 2002;105(1):39.

26. Yazbeck C, Madelenat P, Ayel JP, et al. Ethanol sclerotherapy: a treatment option for ovarian endometriomas before ovarian stimulation. Reprod Biomed Online. 2009;19(1):121-125.

27. Hsieh CL, Shiau CS, Lo LM, Hsieh TT, Chang MY. Effectiveness of ultrasound-guided aspiration and sclerotherapy with $95 \%$ ethanol for treatment of recurrent ovarian endometriomas. Fertil Steril. 2009;91(6):2709-2713.

28. Aysan E, Bektas H, Kaygusuz A. Efficacy of glycerol in preventing postoperative peritoneal adhesions. J Obstet Gynaecol Res. 2010;36(3):639-645.

29. Aysan E, Bektas H, Ersoz F. A new approach to postoperative peritoneal adhesions: prevention of peritoneal trauma by aloe vera gel. Eur J Obstet Gynecol Reprod Biol. 2010;149(2):195-198.

30. Vipond MN, Whawell SA, Thompson JN, Dudley HA. Effect of experimental peritonitis and ischaemia on peritoneal fibrinolytic activity. Eur J Surg. 1994;160(9):471-477.

\section{Publish your work in this journal}

Drug Design, Development and Therapy is an international, peerreviewed open-access journal that spans the spectrum of drug design and development through to clinical applications. Clinical outcomes, patient safety, and programs for the development and effective, safe, and sustained use of medicines are a feature of the journal, which

\section{Dovepress}

has also been accepted for indexing on PubMed Central. The manuscript management system is completely online and includes a very quick and fair peer-review system, which is all easy to use. Visit http://www.dovepress.com/testimonials.php to read real quotes from published authors. 